\title{
Circuito STEAM: Oficina mão na massa para docentes da Educação Profissional durante a pandemia
}

\author{
Esteic Janaina Santos Batista ${ }^{1}$, Cláudia Maia Dezan ${ }^{1}$, Heloisa Fitz Cabral ${ }^{1}$, \\ Reinaldo Camargo da Silva ${ }^{1}$
}

\author{
${ }^{1}$ Serviço Nacional de Aprendizagem Comercial de Mato Grosso do Sul \\ Departamento Regional (SENAC MS) \\ Caixa Postal 15.064 - 79.002-081 - Campo Grande - MS - Brasil \\ \{esteic.batista, claudiadezan, heloisa.cabral, reinaldo.silva\}@ms.senac.br
}

\begin{abstract}
The development of soft skills such as creativity, problem solving, leadership, mastery of technologies, resilience, among others, is increasingly essential for the labor market, requiring them to be worked on in education at all levels. In Professional Education, it has an even greater weight, since the objective is to train for work, with a good part of young people who are starting their professional careers assisted. STEAM Science, Technology, Engineering, Arts and Mathematics is a methodology that promotes hands-on work, which engages students and allows teachers to work in a transdisciplinary and multidisciplinary way, while contributing to the development of soft skills. This work presents a STEAM workshop for training Professional Education teachers from the most diverse courses of an institution and discusses the final result that was the proposition of inserting STEAM projects in learning situations of the Curricular Units of the courses in which these teachers work.
\end{abstract}

Resumo. O desenvolvimento das soft skills como criatividade, resolução de problemas, liderança, domínio de tecnologias, resiliência, dentre outros é cada vez mais imprescindivel para o mercado de trabalho, necessitando que sejam trabalhados na educação em todos os níveis. Na Educação Profissional tem um peso ainda maior, uma vez que o objetivo é formar para o trabalho, sendo uma boa parte dos atendidos jovens que estão iniciando sua carreira profissional. O STEAM Science, Technology, Engineering, Arts and Mathematics é uma metodologia que promove o trabalho mão na massa, que engaja os estudantes e que permite ao docente trabalhar de forma transdisciplinar e multidisciplinar, ao mesmo tempo em que contribui para o desenvolvimento das soft skills. Este trabalho apresenta uma oficina STEAM de formação de professores da Educação Profissional dos mais diversos cursos de uma Instituição e discute o resultado final que foi a proposição da inserção de projetos STEAM em situações de aprendizagem das Unidades Curriculares dos cursos em que estes docentes que atuam.

\section{Introdução}

A tecnologia faz-se presente em diversos âmbitos da nossa vida facilitando e agilizando diversas atividades cotidianas com uso de ferramentas cada vez mais avançadas como: Inteligência Artificial, Processamento de Imagens, Redes Disruptivas, Realidade Virtual 
e Aumentada, que permite que sistemas e aplicativos nos forneçam conteúdos cada mais direcionados com nosso perfil, preferências, interesses, conhecimentos prévios, em diversos âmbitos da nossa vida: lazer, educação e trabalho, favorecendo economia de tempo e recursos.

Anualmente, o Fórum Econômico Mundial divulga um relatório Chamado "The Future of Jobs Report" elaborado por executivos, empresários e pesquisadores do mundo inteiro, onde discutem sobre vários temas conectados ao futuro do trabalho e assim criase conteúdo de alta qualidade e relevância, trazendo competências que estão em alta e que serão mais valorizadas nos próximos anos. No Fórum de 2020 foram elencadas dez habilidades para o mercado de trabalho até 2025 sendo: 1) pensamento analítico e inovação, 2) aprendizagem ativa e estratégias de aprendizagem, 3) resolução de problemas complexos, 4) pensamento crítico e análise, 5) criatividade, originalidade e iniciativa, 6) liderança e influência social, 7) uso, monitoramento e controle de tecnologia, 8) design e programação de tecnologia, 9) resiliência, tolerância ao estresse e flexibilidade e 10) raciocínio, resolução de problemas e ideação que estão vinculadas a quatro principais tipos de habilidades sendo: solução de problemas, auto gerenciamento, trabalhar com pessoas e uso e desenvolvimento de tecnologia [Forum 2020].

Estas habilidades são conceituadas por Soft Skills que são competências comportamentais e estão relacionadas à capacidade do indivíduo interagir com outras pessoas incluindo a capacidade de se adaptar a novas e complexas situações no trabalho. Por outro lado, as Hard Skills também conhecidas como habilidades técnicas, consistem em conhecimento técnico e necessários para o trabalho, como por exemplo, conquistas discriminadas em um currículo, tais como nível de formação, experiência de trabalho, conhecimento e nível de especialização. Elas são específicas, facilmente justificáveis e mensuráveis, podem ser aprendidas e aperfeiçoadas no decorrer dos anos [Penhaki et al. 2019].

Diante deste cenário, torna-se necessário que a educação acompanhe esta evolução para formar cidadãos críticos e preparados para este novo mercado de trabalho, para proporcionar uma formação baseada na aquisição de conhecimentos e também o desenvolvimento das habilidades necessárias na sociedade da informação. Para isso faz-se necessário que sejam trabalhadas metodologias e atividades que favoreçam o desenvolvimento das Soft Skills.

Sendo assim, é necessário que seja repensado o papel do docente frente a estes novos desafios para que ele se aperfeiçoe ao longo da sua formação inicial e continuada algumas competências e habilidades condizentes com as demandas da sociedade atual, principalmente no quesito da utilização de tecnologias diversas em suas práticas educativas, tornando as aulas mais atrativas e engajadoras para os alunos. Este contexto faz com que as instituições de ensino reestruturem aspectos metodológicos relativos ao processo de ensino-aprendizagem e, sobretudo, repensem e modifiquem a estrutura da sua formação docente [Santos and Teixeira 2019].

STEAM é uma sigla em inglês para Science, Technology, Engineering, Arts and Mathematics, em português Ciência, Tecnologia, Engenharia, Artes e Matemática. Essa metodologia orienta projetos educacionais voltados para o desenvolvimento de competências do século XXI de forma mais interativa e autônoma, tornando os alunos mais ativos em sua aprendizagem, seguindo as etapas: investigar, descobrir, conectar, criar e, 
refletir [dos Santos Silva et al. 2019].

A Educação Profissional tem como foco o desenvolvimento de competências e habilidades técnicas para suprir a demanda do mercado de trabalho, sendo oferecidos cursos para jovens e adultos, independente de escolaridade, com o objetivo de qualificação e requalificação profissional. Neste sentido, faz-se necessário incorporar metodologias e práticas que visem o desenvolvimento das Soft Skills nos alunos para atender as demandas deste mercado ao mesmo tempo que tornam-se cidadãos mais críticos e conscientes.

Diante deste contexto, este artigo apresenta uma oficina de STEAM ofertada para docentes da Educação Profissional. A oficina abrangeu no total 17 encontros com duração de 4 horas cada, em que foram desenvolvidos projetos "mão na massa", sendo a etapa final da oficina a inserção destes projetos ou outros correlatos nas situações de aprendizagem dos diversos cursos do Serviço Nacional de Aprendizagem Comercial (SENAC) de Mato Grosso do Sul (MS) com o objetivo do desenvolvimento das soft skills nos alunos.

\section{Referencial Teórico}

Essa seção discute a definição e diferenciação da metodologia STEM e STEAM, e justifica a escolha dos autores pelo termo STEAM na pesquisa apresentada de acordo com os elementos de competência e Marcas Formativas do Modelo Pedagógico do SENAC.

\subsection{Modelo Pedagógico do SENAC}

O SENAC oferece Cursos Técnicos, Qualificação Profissional, Programas de Aprendizagem Profissional e cursos de Formação Inicial e Continuada voltados para o Comércio de Bens, Serviços e Turismo. O Modelo Pedagógico Senac (MPS) tem como objetivo o desenvolvimento de competências para que o profissional formado evidencie domínio técnico-científico em seu campo profissional, tenha visão crítica sobre a realidade, atuando com foco em resultados [SENAC 2015c].

No MPS, a unidade curricular de um curso é a própria competência, que é definida por uma ação/fazer profissional observável, potencialmente criativo, que articula conhecimentos (hard skills), habilidades, atitudes e valores (soft skills) permitindo o seu desenvolvimento contínuo. São exemplos de competência/unidade curricular: a) Recepcionar e atender clientes no meio de hospedagem, b) Realizar a venda, c) Analisar requisitos e funcionalidades da aplicação [SENAC 2015b].

O aluno é avaliado por meio de menção para cada um dos indicadores da Unidade Curricular. Por exemplo, a Unidade Curricular Analisar requisitos e funcionalidades da aplicação do Curso Técnico em Desenvolvimento de Sistemas apresenta indicadores como: a) Define os objetivos do projeto, de acordo com as necessidades do cliente e público-alvo, b) Aplica técnicas de modelagem de Engenharia de Software, c) Testa hipóteses com o usuário final, conforme análise de requisitos.

Os indicadores são avaliados durante o desenvolvimento da Unidade Curricular por meio de menções, sendo: a) atendido: o aluno evidencia o fazer profissional expresso no indicador avaliado, atendendo de forma satisfatória às condições descritas em seu contexto; b) parcialmente atendido: atende ao fazer profissional expresso no indicador, mas não atende ao contexto descrito; ou vice versa ou ainda não de forma plena; c) não atendido: o aluno ainda não evidencia o fazer profissional expresso no indicador avaliado, 
nem no seu nível mais simples. Quando observadas em um aluno as menções PA (Parcialmente Atendido) ou NA (Não Atendido), devem ser efetivadas ações de recuperação paralela para que as dificuldades sejam superadas e novas oportunidades de aprendizado e avaliação [SENAC 2015a].

Essa organização do MPS e forma de avaliação favorecem e facilitam o uso de metodologias ativas de aprendizagem como Aprendizagem Baseada em Problemas, Aprendizagem Baseada em Casos, Sala de Aula Invertida, Gamificação e Aprendizagem Baseada em Projetos, e recentemente a inserção do STEAM nos cursos.

\subsection{STEM E STEAM}

STEM é um acrônimo para Science, Technology, Engineering and Mathematics, em português Ciência, Tecnologia, Engenharia e Matemática definido pela primeira vez como um termo educacional pela National Science Foundation (NSF) no início do ano 2000. Pode ser definida como uma metodologia que promove a integração destas áreas para uma abordagem interdisciplinar nas escolas, pois oferece aos alunos uma forma de trabalhar com conteúdos de diversas áreas de forma integrada e contextualizada com a realidade em que está inserido, em vez de aprender pedaços fragmentados de conhecimentos e práticas sobre o assunto [Dugger 2010].

Posteriormente, foi acrescido o A de Artes no acrônimo, criando o novo termo STEAM Science, Technology, Engineering, Arts and Mathematics em português Ciência, Tecnologia, Engenharia, Artes e Matemática, com o propósito incorporar a contribuição das áreas das humanidades, abrangendo o design criativo para processos de criação de ideias inovadoras, englobando as linguagens, música, artes e educação física com o objetivo de oferecer às escolas maneiras de desenvolver valores juntamente com os conteúdos. O STEAM ganha nuances pedagógicas em vários países, traduzidas por um modo de fazer com atenção voltada para a curiosidade e a inventividade [SENAC 2021] [Tokarnia 2021].

A metodologia STEAM esta atrelada ao movimento ou cultura maker que vêm ganhando impulso nos espaços escolares, denominado no Brasil também como metodologia "mão na massa". A cultura Maker tem a premissa que qualquer pessoa, especialista ou não, possa construir, consertar, transformar ou fabricar diferentes tipos de objetos e projetos, utilizando materiais de baixo custo e com as próprias mãos. Nesses locais, encontram-se os makers, ou simplesmente "fazedores", que são os seguidores deste movimento [Vaz and Júnior 2020].

A UNESCO ainda hoje utiliza o termo "Educação em STEM" para designar o foco em ciência, tecnologia, engenharia e matemática, caracterizando-o como chave para preparação de estudantes para o mundo do trabalho, permitindo sua entrada nas carreiras baseadas nessas áreas. No entanto, neste trabalho definimos como STEAM pois o objetivo da utilização da metodologia em projetos dos cursos de diferentes áreas é o desenvolvimento da criatividade, as soft skills e das marcas formativas presentes no Modelo Pedagógico do SENAC, sendo: domínio técnico científico, visão crítica, atitude empreendedora, sustentável e colaborativa.

\section{Trabalho Correlatos}

Uma revisão não sistemática de literatura foi realizada a fim de verificar os trabalhos correlatos à esta pesquisa no Google Acadêmico por meio da String: (STEM OR STEAM 
OR (movimento AND maker) OR (mão and massa)) AND (formação OR oficina OR curso) AND (docentes OR professores) AND educação AND (técnica OR profissional).

Verificou-se que o foco da formação docente e aplicação em sala de aula do STEAM e do STEM, bem como a aprendizagem mão na massa ganharam força no Brasil na Educação Básica. No ensino superior ou tecnológico a metodologia tem sido empregada em cursos da área tecnológica atrelando-se aos seus conhecimentos como lógica de programação e automação.

No contexto da Educação Profissional, [Melendez 2019] investiga os reflexos das atividades de produção de jogos digitais atrelado ao movimento game maker no aprendizado do estudante do curso técnico em informática integrado ao ensino médio.

O trabalho de [de Moraes Martines et al. 2019] analisa a trajetória de um grupo que atua de forma interdisciplinar e transdisciplinar na área de Ensino de Ciências, principalmente com a formação de professores de Biologia, Química, Física e Informática, incorporando Artes e Engenharia das escolas de ensino básico e nas licenciaturas destas áreas em parceria com redes e universidades. A metodologia STEAM foi adotada como forma de trabalhar a interdisciplinaridade, em múltiplos caminhos, reconectando os conhecimentos para dar vida à criatividade na solução de problemas reais.

Já [Nascimento 2020] apresenta a proposta mais próxima deste trabalho ao apresentar uma alternativa integrando metodologias ágeis,a metodologia STEAM e a gestão de projetos para que os discentes de uma Escola Técnica Estadual desenvolvessem as competências práticas necessárias e previstas no currículo de um curso técnico pertencente ao eixo tecnológico "Controle e Processos Industriais" de forma remota durante a pandemia. A prática fez uso de uma plataforma de livre acesso onde os discentes desenvolveram pequenos projetos com sensores e atuadores baseados na programação de uma plataforma microcontrolada. A cada aplicação cumprida, o aluno adquire uma competência técnica necessária para capacitá-lo no desenvolvimento de um projeto final que tratava-se da montagem de um manipulador robótico ou um robô móvel na própria plataforma.

Como podemos observar os trabalhos no contexto da Educação Profissional envolvendo o STEAM são cursos da área de tecnologia integrado ao Ensino Médio, sendo apenas o trabalho de [Nascimento 2020] mais próximo desta pesquisa, mas não envolvendo formação de professores. Sendo assim, reforça-se a importância deste trabalho que relata a formação de docentes da Educação Profissional de diversas áreas com enfoque na aplicação do STEAM em situações de aprendizagem destes diversos cursos a fim de desenvolver as soft skills e quando possível criando conexão com as hard skills do curso.

\section{Metodologia}

Este projeto foi dividido em 4 etapas. Na primeira etapa, a oficina de STEAM foi ofertada de forma remota devido à pandemia COVID 19 que impediu reunir presencialmente todos os docentes das cinco unidades operativas do SENAC MS sendo uma das unidades na capital (Campo Grande) e quatro unidades do interior (Três Lagoas, Corumbá, Dourados, Ponta Porã).

O facilitador da oficina de uma empresa externa que estava ministrando a oficina encontrava-se em outro estado, São Paulo, e deu suporte aos grupos que estavam reuni- 
dos presencialmente em suas respectivas unidades divididos em grupos de 4 a 6 pessoas respeitando as medidas de biossegurança. Os projetos STEAM desenvolvidos durante a oficina são disponibilizados na plataforma Microsoft Educator Center da trilha Hacking STEM $^{1}$.

No total 44 pessoas do corpo pedagógico participaram da formação sendo 6 coordenadores pedagógicos de curso, 34 docentes e 4 analistas pedagógicos que mediaram a oficina. Os grupos foram divididos, na maior parte, de acordo com o segmento e eixo do curso que atuam.

Os grupos foram divididos em dois dias da semana, representados nas Tabelas $1 \mathrm{e}$ 2 respectivamente como Dia 1 e Dia 2. Os projetos executados em cada um dos dias eram diferentes de forma a ter maior coerência com as áreas do grupo. Como podemos observar, no Dia 1 participaram os grupos com docentes e coordenadores dos cursos da área da Saúde e no Dia 2 grupos de participantes dos cursos da área de Gestão, Informática e do segmento de Aprendizagem. Em alguns casos, por se tratar de uma unidade operativa pequena ou indisponibilidade do docente, este foi alocado em outro grupo conforme necessidade. Os seguintes projetos da trilha Hacking STEM foram desenvolvidos pelos grupos:

- Party Lights! $!^{2}$ projeto consistia em criar um circuito com manipulação de luzes.

- Mão Robótica ${ }^{3}$ : construção de uma mão robótica com papelão, canudos e kit de eletrônica com comunicação com um protótipo de uma luva.

- Cerébro ${ }^{4}$ : construção de modelos para entender e mitigar a lesão cerebral.

- Profundidade dos oceanos ${ }^{5}$ : protótipo para medir a profundidade dos oceanos utilizando sensor ultrassônico.

- Como os tubarões nadam ${ }^{5}$ : sistema de coordenadas em 3D usando modelos físicos e digitais de tubarões para entender guinadas, inclinação e rotação.

- Medidor de qualidade da água ${ }^{6}$ : construção de sensores de condutividade elétrica usando fios e canudos para medir o impacto da atividade humana em ecossistemas de água doce.

- Meias para astronautas ${ }^{7}$ : projeto de meias para proteger os pés dos astronautas na microgravidade.

A Oficina teve ao total oito encontros de quatro horas para os grupos do Dia 1, totalizando 32 horas; e nove encontros de quatro horas para os grupos dia Dia 2, totalizando 36 horas. Os encontros iniciavam de forma síncrona com todos os grupos em seus respectivos dias nas equipes na plataforma Microsoft Teams para contextualização do projeto a ser desenvolvido. Posteriormente, os grupos eram separados em canais para iniciar a execução do projeto que contava com vídeo aulas gravadas e disponibilizadas no SharePoint como apoio e os participantes poderiam sanar as dúvidas com o facilitador

\footnotetext{
${ }^{1}$ https://education.microsoft.com/pt-br/hackingStem

${ }^{2}$ Party Lights: https://www.microsoft.com/en-us/education/education-workshop/party-lights.aspx.

${ }^{3}$ Mão Robótica: https://www.microsoft.com/pt-br/education/education-workshop/robotic-hand.aspx.

${ }^{4}$ Cerébro:

simulator.aspx.

${ }^{5}$ Profundidade dos Oceanos: https://www.microsoft.com/pt-br/education/oceans/explore.

${ }^{6}$ Medidor da qualidade da água: https://www.microsoft.com/pt-br/education/educationworkshop/conductivity-sensor.aspx

${ }^{7}$ Meia: https://education.microsoft.com/en-us/lesson/d1c4fc23
} 
Tabela 1. Divisão dos grupos para a oficina do Dia 1.

\begin{tabular}{|c|c|c|}
\hline \multicolumn{3}{|c|}{ Dia 1} \\
\hline Unidade Operativa & Grupo & Participante \\
\hline & & Coordenação \\
\hline & & Enfermagem \\
\hline Horto & Grupo 1 & Podologia \\
\hline & & Aprendizagem \\
\hline & & Analista Pedagógico \\
\hline Horto & Grupo 2 & $\begin{array}{l}\text { Informática } \\
\text { Estética } \\
\text { Aprendizagem } \\
\text { Analista Pedagógico }\end{array}$ \\
\hline Corumbá & Grupo 3 & $\begin{array}{l}\text { Coordenação } \\
\text { Estética/Beleza } \\
\text { Enfermagem } \\
\text { Enfermagem }\end{array}$ \\
\hline Três Lagoas & Grupo 4 & $\begin{array}{l}\text { Coordenação } \\
\text { Assistente de Coordenação } \\
\text { Aprendizagem } \\
\text { Enfermagem }\end{array}$ \\
\hline $\begin{array}{l}\text { Dourados e Ponta } \\
\text { Porã }\end{array}$ & Grupo 5 & $\begin{array}{l}\text { Coordenação } \\
\text { Cabeleireiro } \\
\text { Aprendizagem } \\
\text { Análises Clínicas }\end{array}$ \\
\hline
\end{tabular}

por meio do seu canal. Ao final de cada encontro as equipes reuniam-se novamente no canal geral para compartilhar suas experiências, feedbacks e relatar sobre como o projeto poderia ser aplicado nas aulas dentro de sua respectiva área de atuação.

Na segunda etapa foi proposta uma atividade aos participantes: reunidos em grupos do mesmo segmento ou área, estes deveriam escolher uma situação de aprendizagem de uma ou mais Unidades Curriculares de cursos que atuam de forma a trabalhar os elementos da competência seja por meio do desenvolvimento das soft skills (habilidades, atitudes e valores) e quando possível das hard skills (conhecimentos) com um projeto STEAM. Estes projetos poderiam ser um dos que foram trabalhados na oficina ou uma nova proposição. Para isso, fez-se necessário um encontro remoto com todos os participantes da oficina com duração de uma hora para explicação da atividade. Os grupos tiveram duas semanas para enviar a atividade solicitada e apresentá-la em um segundo encontro com duração de uma hora e trinta e minutos, também realizado de forma síncrona no Teams.

$\mathrm{Na}$ terceira etapa, os analistas pedagógicos realizaram a validação e feedback das situações de aprendizagem propostas pelos docentes, para que estes possam aplicar a metodologia de forma piloto nas aulas.

A quarta etapa, consiste na adaptação das situações de aprendizagem após aplicação do piloto em sala de aula e inserção destas no Plano de Trabalho Docente (PTD) para que seja utilizado como referência nos cursos ofertados. Na quinta e última etapa acontecerá a multiplicação da oficina aos docentes que não participaram da formação, por serem recém admitidos ou por estarem lotados em aulas ou em estágios nos horários da oficina. Desta forma, espera-se que o conhecimento possa ser compartilhado entre os pares, permitindo o desenvolvimento contínuo dos docentes. 
Tabela 2. Divisão dos grupos para a oficina do Dia 2.

\begin{tabular}{|c|c|c|}
\hline \multicolumn{3}{|c|}{ Dia 2} \\
\hline Unidade Operativa & Grupo & Participante \\
\hline \multirow{6}{*}{ Horto } & \multirow{6}{*}{ Grupo 1} & Aprendizagem \\
\hline & & Aprendizagem \\
\hline & & Aprendizagem \\
\hline & & Aprendizagem \\
\hline & & Coordenação \\
\hline & & Analista Pedagógico \\
\hline \multirow{5}{*}{ Horto } & \multirow{5}{*}{ Grupo 2} & Informática \\
\hline & & Informática \\
\hline & & Informática \\
\hline & & Coordenação \\
\hline & & Analista Pedagógico \\
\hline \multirow{5}{*}{ Horto } & \multirow{5}{*}{ Grupo 3} & Aprendizagem \\
\hline & & Segurança do Trabalho \\
\hline & & Gestão \\
\hline & & Gestão \\
\hline & & Analista Pedagógico \\
\hline \multirow{4}{*}{ Corumbá } & \multirow{4}{*}{ Grupo 4} & Gestão \\
\hline & & Gestão \\
\hline & & Enfermagem \\
\hline & & Enfermagem \\
\hline \multirow{4}{*}{$\begin{array}{c}\text { Dourados e Ponta } \\
\text { Porã }\end{array}$} & \multirow{4}{*}{ Grupo 5} & Aprendizagem \\
\hline & & Aprendizagem \\
\hline & & Enfermagem \\
\hline & & Gastronomia \\
\hline
\end{tabular}

\section{Análise dos Resultados}

Durante os encontros os docentes observaram diversas conexões dos projetos desenvolvidos com unidades curriculares que atuam. Foi ressaltado pelos mediadores que o objetivo da inserção do projeto do STEAM não era o ensino da eletrônica ou programação, mas sim o desenvolvimento das soft skills como colaboração, criatividade, engajamento, empatia, liderança, entre outras, e quando possível das hard skills.

Como resultado da oficina, foram inseridos os projetos STEAM em vinte situações de aprendizagens em diversos cursos ofertados no SENAC MS.

Figura 1. Situações de Aprendizagem propostas

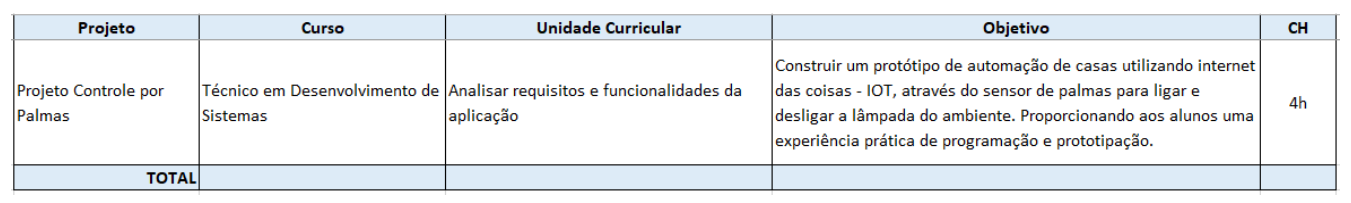

As situações de aprendizagem propostas são apresentadas nas Tabelas 2, 3, 4 e 5 com o nome do curso, unidade curricular, objetivo do projeto e carga horária para o seu desenvolvimento. Os projetos propostos neste primeiro momento foram os mesmos trabalhados durante a oficina, sendo que alguns indicaram uma pequena alteração, com exceção do projeto Controle por Palmas descrito na Figura 1, este foi pilotado em sala de aula no curso Técnico em Desenvolvimento de Sistemas, utilizando gamificação, fator chave para engajar os alunos, o que foi evidenciado na pesquisa realizada ao final da experiência tendo a satisfação unânime da turma. Devido à natureza do curso, os alunos programaram o protótipo, colocando em prática o conhecimento presente no curso. 
Figura 2. Situações de Aprendizagem propostas

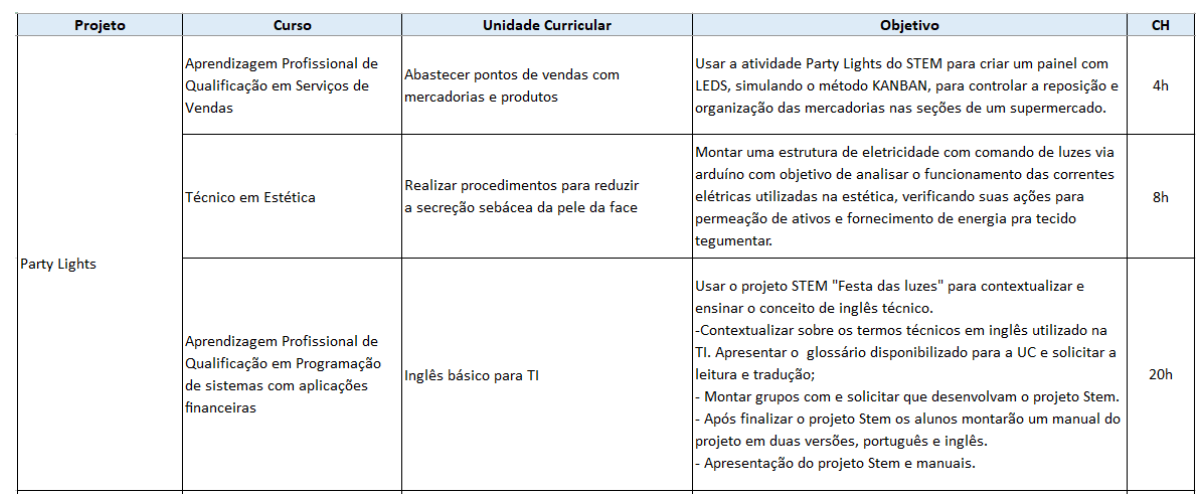

Conforme demonstrado nestas tabelas, a metodologia STEAM permite desenvolver projetos para trabalhar as soft skills e hard skills, podendo ser desenvolvida de maneira interdisciplinar e transdisciplinar entre os cursos Barbeiro, Cabeleireiro, Maquiador, Depilador e Técnico em Estética que possuem uma Unidade Curricular similar. O projeto Meia Microgravidade consegue contemplar as especificidades destes cursos, conforme apresentado na tabela da Figura 5.

Figura 3. Situações de Aprendizagem propostas

\begin{tabular}{|c|c|c|c|c|}
\hline Projeto & Curso & Unidade Curricular & Objetivo & $\mathrm{CH}$ \\
\hline \multirow{4}{*}{ Qualidade da Água } & Técnico em Enfermagem & $\begin{array}{l}\text { Executar açōes de prevenção, promoção, } \\
\text { proteção, reabilitaçăo e recuperação da } \\
\text { saúde }\end{array}$ & $\begin{array}{l}\text { Criação do Projeto para trabalhar sobre a importância da } \\
\text { qualidade da água nos serviços de saúde, em que a partir do } \\
\text { projeto desenvolvido os alunos irão analisar a qualidade da água } \\
\text { dos diferentes locais (bebedouro, água suja, copa, etc.) }\end{array}$ & $4 \mathrm{~h}$ \\
\hline & \begin{tabular}{|l} 
Aprendizagem Profissional de \\
Qualificação em Serviços \\
Administrativos
\end{tabular} & $\begin{array}{l}\text { Organizar e operacionalizar procedimentos } \\
\text { de recepção }\end{array}$ & $\begin{array}{l}\text { O aluno assume o papel de um hidrólogo que monitora a } \\
\text { qualidade da água na represa local. }\end{array}$ & $8 \mathrm{~h}$ \\
\hline & $\begin{array}{l}\text { Aprendizagem Profissional de } \\
\text { Qualificação em Serviços em } \\
\text { Postos de Combustiveis }\end{array}$ & $\begin{array}{l}\text { Manusear produtos e equipamentos de } \\
\text { trabalho }\end{array}$ & $\begin{array}{l}\text { Com o projeto os alunos irão analisar a qualidade da água nos } \\
\text { postos de combustiveis. }\end{array}$ & $6 \mathrm{~h}$ \\
\hline & Cabeleireiro & Higienizar e modelar os cabelos & $\begin{array}{l}\text { Analisar e Discutir a influência do PH da Água ou até mesmo } \\
\text { do produto que está sendo utilizado nos fios e/ou couro } \\
\text { cabeludo. Seus beneficios, maleficios e quando se deve ou } \\
\text { não usar tais produtos de acordo com o seu PH. }\end{array}$ & $4 \mathrm{~h}$ \\
\hline $\begin{array}{l}\text { Sensor Ultrassônico- } \\
\text { Experiência Imersiva } \\
\text { dos oceanos }\end{array}$ & Cozinheiro & $\begin{array}{l}\text { Controlar e organizar estoques em } \\
\text { ambiente de manipulação de alimentos }\end{array}$ & $\begin{array}{l}\text { Um estoque bem organizado é de extrema importância para o } \\
\text { setor produtivo. Com a construção do barco, que tem a finalidade } \\
\text { de trabalhar a profundidade, poderemos aplicar na organizaçăo e } \\
\text { armazenamento de materiais, produtos e insumos. }\end{array}$ & $8 \mathrm{~h}$ \\
\hline
\end{tabular}

Observamos que um mesmo projeto atende a diversos cursos de natureza e objetivos diferentes conforme apresentado nas Tabelas 2, 3 e 4, como por exemplo, o projeto Party Lights, que no curso que tem foco em Vendas, ele é trabalhado como um controle de reposição, incrementando outros elementos no projeto. Já no curso de Estética faz analogia com o sistema tegumentar do corpo humano e no curso de programação, é utilizado para o desenvolvimento do inglês técnico. Esses exemplos demonstram o quanto a metodologia STEAM é adaptável e pode ser utilizado em diferentes momentos de um curso, adequando aos objetivos de cada aula, bem como seu conhecimento, habilidades e atitudes/valores.

\section{Considerações Finais}

A utilização das soft skills como criatividade, resolução de problemas, liderança, domínio de tecnologias, resiliência, dentre outras são cada vez mais imprescindíveis para o mer- 
Figura 4. Situações de Aprendizagem propostas

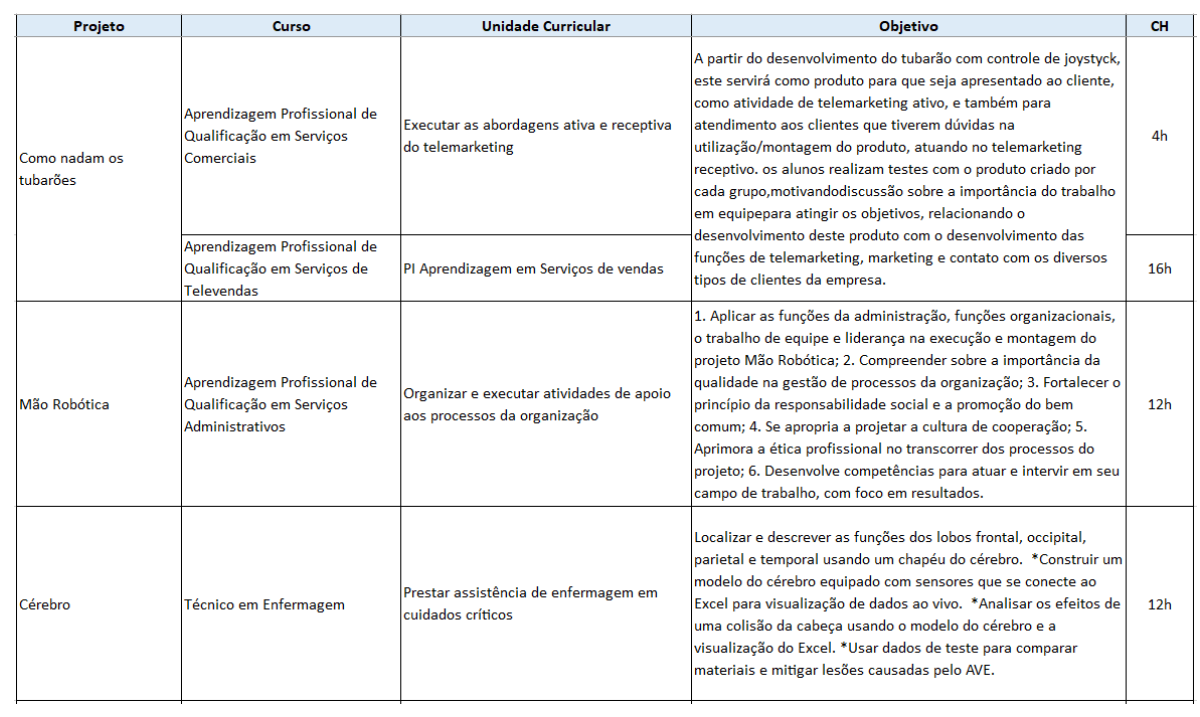

Figura 5. Situações de Aprendizagem propostas

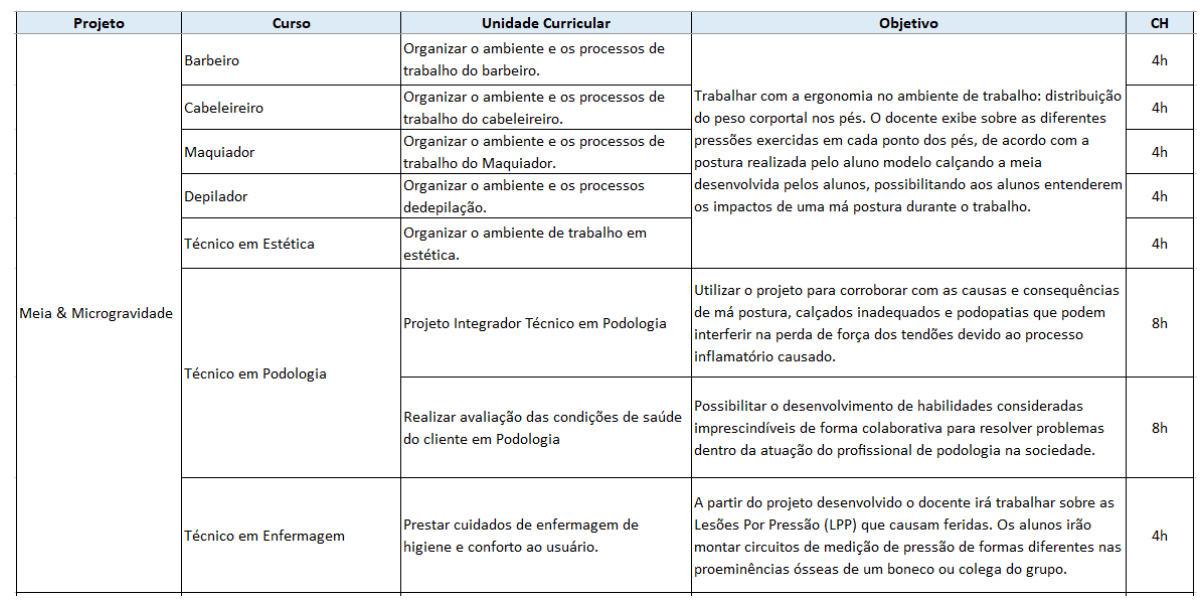

cado de trabalho, necessitando que sejam desenvolvidas na educação em todos os níveis. O STEAM (Science, Technology, Engineering, Arts and Mathematics) é uma metodologia que promove o trabalho mão na massa, que engaja os estudantes e que permite ao docente trabalhar de forma transdisciplinar e multidisciplinar ao mesmo tempo que contribui com o desenvolvimento das soft skills.

Este trabalho evidenciou a possibilidade de desenvolver de forma criativa e envolvente por meio da metodologia STEAM as habilidades comportamentais, sendo notória a empolgação dos docentes durante a execução dos projetos ao perceber que poderiam aplicar a metodologia nas suas respectivas áreas, uma vez que enxergavam a mesma como possível apenas para cursos da área de tecnologia da informação.

O projeto proposto, intitulado como Circuito STEAM, tem como premissa a retroalimentação do ciclo apresentado, no qual os docentes já capacitados farão a multiplicação para seus pares e criarão novas situações de aprendizagem a partir das experiências já vivenciadas. Pretende-se que a partir de uma maturidade adquirida ao longo do tempo, docentes e alunos desenvolvam novos projetos STEAM nos seus cursos para 
que possam atender a uma demanda real do mercado de trabalho e/ou da sociedade.

\section{Referências}

de Moraes Martines, E. A. L., Dutra, L. B., and de Oliveira Borges, P. R. (2019). Educiência: da interdisciplinaridade ao steam. REAMEC-Rede Amazônica de Educação em Ciências e Matemática, 7(3):92-110.

dos Santos Silva, D. E., Sobrinho, M. C., and Valentim, N. (2019). Steam and digital storytelling: a case study with high school students in the context of education 4.0. In Brazilian Symposium on Computers in Education (Simpósio Brasileiro de Informática na Educação-SBIE), volume 30, page 159.

Dugger, W. E. (2010). Evolution of stem in the united states. In 6th biennial international conference on technology education research, volume 10.

Forum, W. E. (2020). The future of jobs report 2020. World Economic Forum Geneva.

Melendez, T. T. (2019). O movimento game maker na educação profissional e tecnológica: produção de jogos digitais e seus reflexos no aprendizado dos técnicos em informática.

Nascimento, J. M. (2020). Aplicação da metodologia steam através da robótica: Uma solução aos desafios da educação profissional durante a pandemia de covid-19.

Penhaki, J. d. R. et al. (2019). Soft skills na indústria 4.0. Master's thesis, Universidade Tecnológica Federal do Paraná.

Santos, A. and Teixeira, A. (2019). A formação de professores e a importância da fluência tecnológica digital em meio ao cenário do século xxi. In Anais do Workshop de Informática na Escola, volume 25, pages 831-838.

SENAC, D. (2015a). Coleção de Documentos Técnicos do Modelo Pedagógico Senac: Avaliação.

SENAC, D. (2015b). Coleção de Documentos Técnicos do Modelo Pedagógico Senac: Competência.

SENAC, D. (2015c). Coleção de Documentos Técnicos do Modelo Pedagógico Senac: Concepções e princípios.

SENAC, D. N. (2021). O uso do STEAM na nova proposta do programa de aprendizagem do Senac.

Tokarnia, M. (2021). Ciências exatas podem ser ensinadas com humanidades; conheça o conceito STEAM. Disponível em: https://agenciabrasil.ebc.com.br/educacao/noticia/2017-01/ciencias-exatas-podemser-ensinadas-com-humanidades-conheca-o-conceito.

Vaz, C. L. D. and Júnior, E. d. P. N. (2020). O lugar da aprendizagem criativa: Uma experiência com a matemática mão na massa. REMATEC, 15:137-155. 